\title{
SEMANAS ACADÊMICAS COMO POSSIBILIDADES DE EFETIVAÇÃO DO TRÂNSITO DISCIPLINAR: UMA EXPERIÊNCIA NA ESCOLA DE ARQUITETURA E DESIGN DA PUCPR
}

\author{
Luciane Hilu \\ PUCPR \\ luciane.hilu@pucpr.br
Rita de Cássia Veiga Marriott
UTFPR
ritamarriott@yahoo.co.uk \\ Patricia Lupion Torres \\ PUCPR \\ patorres@terra.com.br
}

Resumo: Com o objetivo de promover o sentido de complexidade e reintegração (ou abolição) disciplinar, neste estudo de caso pesquisamos como as formas de intercâmbio disciplinar, como a multidisciplinaridade, a pluridisciplinaridade, a interdisciplinaridade, a transdisciplinariedade e a metadisciplinaridade (ZABALA, 2002) estão sendo estimuladas pelas Semanas Acadêmicas propostas pela Escola de Arquitetura e Design da PUCPR (Pontifícia Universidade Católica do Paraná) e como este intercâmbio disciplinar está sendo apreendido e vivenciado pelos alunos. Participantes voluntários, alunos de todos os períodos dos cursos de Design Digital, Design Gráfico, Design de Produto, Design de Moda e Arquitetura e Urbanismo responderam a um questionário de avaliação online após os eventos a respeito da sua percepção quanto à efetivação do intercâmbio disciplinar promovido pelas Semanas Acadêmicas de seus cursos, Curso de Design (Charneira) e de Curso de Arquitetura e Design (Sincronicidade). foram analisadas quali-quantitativamente perguntas sobre a interação de sua Semana Acadêmica com as outras áreas de estudo, a contribuição deste evento no desenvolvimento holístico e global dos participantes, a articulação dos saberes acadêmicos e não acadêmicos, bem como quais atividades, dentre oficinas, palestras e mesas-redondas, mais proporcionaram a transdisciplinariedade na Escola e minimizaram a fragmentação dos saberes. Os resultados revelam que a forma de intercâmbio mais reconhecida é a Interdisciplinaridade, mas apontam, ainda que de forma inconsciente e não sistematizada, uma leve tendência 
à promoção da transdisciplinaridade, indicando que as Semanas Acadêmicas têm o potencial de promover o rompimento dos paradigmas tradicionais de ensino.

Palavras-chave: Design, semanas acadêmicas, trânsito disciplinar

\begin{abstract}
In order to foster a sense of complexity and reintegration (or abolition) disciplines, this case study researched the forms of disciplinary exchange such as multidisciplinarity, pluridisciplinarity, interdisciplinarity, transdisciplinarity and metadisciplinaridade (Zabala, 2002) and how they are being stimulated by Academic Weeks proposed by the School of Architecture and Design at PUCPR (Pontifical Catholic University of Paraná) and how this disciplinary exchange has being perceived and experienced by students. Voluntary participants, students from all periods of the courses of Digital Design, Graphic Design, Product Design, Fashion Design and Architecture answered an online questionnaire evaluated after the events concerning their perception of the effectiveness of the disciplinary exchange promoted by Academic Weeks of their courses, by the course of Design (called Charneira) and by the School of Architecture and Design (called Sincronicidade). Were analyzed qualitative and quantitatively some questions about the interaction of their Academic Weeks with other fields of study, the contribution of these events on an holistic and global development of the participants, the articulation of academic and nonacademic knowledge, and which activities (workshops, lectures and roundtables) provided the transdisciplinarity and minimized the fragmentation of knowledge. The results reveal that the most recognized form of exchange is interdisciplinarity, but pointed out on unconscious and not systematized way, a slight tendency to promote transdisciplinary, indicating that the Academic Weeks have the potential to promote the breakdown of traditional paradigms on education.
\end{abstract}

Keywords: Design, academic weeks, disciplinary transit

\title{
1 INTRODUÇÃO
}

O repensar das práticas educacionais na Escola baseia-se na ideia de que "um bom sistema educativo é aquele que se manifesta sensível às diferentes demandas sociais e às exigências de um mundo em constante evolução" (ZABALA, 2002, pag. 20), o que implica na movimentação contínua dos saberes propostos, na direção oposta da fragmentação do saber, de vertente propedêutica.

Este repensar está sustentado por uma tomada de consciência da mudança do paradigma científico e, por conseguinte, educacional, que supera o paradigma cartesiano adotado ainda em grande parte das escolas. Segundo Morin (2000), o modelo cartesiano não consegue mais tratar dos problemas fundamentais e globais atuais, sendo necessário um novo modelo que tenha como proposta a 
exploração da inteligência geral. Para o autor, quanto mais poderosa é a inteligência geral, maior é a capacidade do indivíduo de tratar de problemas da atualidade.

Refletida na educação, esta ideia vem dando suporte à implementação de uma educação que busca favorecer a aptidão natural da mente para formulações e resoluções de problemas essenciais, rejeitando a disjunção entre as humanidades e as ciências, e a superespecialização das ciências fragmentadas.

Para dar conta dos problemas cada vez mais multidisciplinares, transversais, multidimensionais, transacionais, globais e planetários, Morin (2000) propõe o novo paradigma, no qual o indivíduo deve se perceber e conceber a construção do conhecimento integralmente nos aspectos inerentes ao Contexto, ao Global, ao Multidimensional e ao Complexo. Para tal, deve-se ter em vista que para dar conta do Contexto é necessário situar as informações e os dados em seu contexto para que adquiram sentido; para contemplar o Global é essencial pensar na relação do todo com as partes também, pois não se conhece o todo sem conhecer as partes; com relação ao Multidimensional, é preciso compreender que as unidades são complexas e multidimensionais; e com relação ao Complexo, é necessário enfrentar a complexidade pelo conhecimento pertinente, devendo-se buscar a união entre a unidade e a multiplicidade.

Por esta perspectiva, a escola deve refletir sobre a importância da educação para o desenvolvimento integral da pessoa em todas as suas dimensões: social, interpessoal, pessoal e profissional, independentemente do papel profissional que desenvolverá na sociedade, de modo a capacitá-la a responder às demandas que a sociedade apresentará.

Senso assim, as escolas devem promover sua atuação para que o ensino não exacerbe a supervalorização da disciplina que inibe a construção do ser e do saber global. Paralelamente deve privilegiar o diálogo entre a teoria e a prática, que se perdeu ao longo das vertentes educacionais anteriores. É necessário conectar o ensino com o contexto do aluno, à sua realidade, para que se proceda à aprendizagem significativa devolvendo ao aluno o elo entre o conhecimento científico e o conhecimento cotidiano.

Frente a este desafio, questionam-se os modelos acadêmicos atuais tradicionais de organização curricular por disciplinas e buscam-se propostas para a implementação de uma abordagem holística e global necessária para responder a esta configuração social. Neste questionamento, o aluno passa a ser o centro do processo educativo, e não o conteúdo em si, que, embora fundamental, passa a não ter prioridade. Isto demanda o estabelecimento de novos processos de ensino que tratem os conteúdos não mais de forma fragmentada, disciplinar, estanque e isolada, mas de forma integral e indissociável dos aspectos dimensionais do aluno (sociais, interpessoais, pessoais e profissionais).

Devido a grande dificuldade das escolas em proceder à educação para este novo paradigma surge uma demanda específica de pesquisa com o intuito de levantar quais propostas educacionais estão permitindo a nova integração dos saberes, minimizando a sua fragmentação e restaurando o conhecimento como um elemento holístico. Busca-se compreender, dentro de um nicho educacional específico, quais ações são realizadas na tentativa de reverter a fragmentação e desconexão dos saberes, bem como se estas ações têm alcançado sucesso, seja consciente ou inconscientemente. 
O nicho escolhido para proceder a este estudo de caso foram as ações da Escola de Arquitetura e Design da PUCPR (Pontifícia Universidade Católica do Paraná) que buscam promover o sentido de complexidade e reintegração (ou abolição) disciplinar. Analisou-se também como estas ações estão sendo apreendidas e vivenciadas conscientemente pelos alunos como catalizadoras de um intercâmbio disciplinar.

\section{DESENVOLVIMENTO}

\subsection{Formas de intercâmbio disciplinar}

Pensar a mudança de paradigma educacional para que atenda às necessidades atuais advindas da complexidade tem instigado a alguns autores a buscar a compreensão das relações possíveis entre as disciplinas de forma a repensar seus possíveis intercâmbios. Entre os autores, temos Zabala (2002, p.39), que aponta as relações possíveis como: multidisciplinaridade, pluridisciplinaridade, interdisciplinaridade, metadisciplinaridade e transdisciplinaridade. Para Zabala (2002, p. 32, 33 e 34), a multidisciplinaridade é a forma de intercâmbio mais tradicional. Nela, a organização dos conteúdos das disciplinas ocorre independentemente uma das outras e seu significado pode ser compreendido pela palavra Somativa. Segundo o autor, a pluridisciplinaridade é compreendida como sendo as relações complementares entre disciplinas mais ou menos afins, atrelando à ela a palavra Contiguidade. Com relação à interdisciplinaridade, o autor a entende como o reencontro e a cooperação entre duas ou mais disciplinas, cada qual com seus próprios esquemas conceituais, maneiras de definir os problemas e seus métodos de pesquisa, promovendo em alguns momentos um novo corpo disciplinar, com significado personificado na palavra Interação. Compreende a transdisciplinaridade como o contato e a cooperação entre disciplinas de tal magnitude que ambas acabam por adotar um mesmo conjunto de conceitos fundamentais ou elementos de métodos de pesquisa, ou seja, o mesmo paradigma. É onde ocorre o máximo grau de relações entre disciplinas, promovendo uma integração global dentro de um sistema totalizador, buscando explicar a realidade sem fragmentações. A palavra chave da transdisciplinaridade é a Unificação. Já a metadisciplinaridade, representada pela palavra Libertação, é o prescindir das disciplinas, eliminando o conceito de relações entre elas e se focando no ponto de vista ou perspectiva sobre qualquer situação ou objeto. Seria esta a forma mais adequada de conhecer a realidade complexa, global e holística.

Esta classificação serviu de base para proceder à pesquisa sobre a percepção do trânsito disciplinas nas ações da Escola de Arquitetura e Design, estudo de caso deste artigo.

\subsection{A Escola de Arquitetura e Design}

A Escola de Arquitetura e Design (EArqD) é uma unidade acadêmica criada em 2012 na estrutura da Pontifícia Universidade Católica do Paraná - PUCPR, em uma perspectiva de atualização e inovação do seu Projeto Pedagógico Institucional (PPI). Está no bojo da ideia de organização dos cursos da universidade em Unidades Acadêmicas, intituladas Escolas, nominadas conforme a área de atuação. Um dos principais objetivos da criação das escolas é a possibilidade de integração entre os cursos que definem o contorno de uma área específica do conhecimento. Tais 
integrações são possibilitadas nos diferentes níveis, seja vertical e horizontal, com atividades de pesquisa, ensino e extensão.

Atualmente fazem parte da EArqD os cursos de graduação de Arquitetura e Urbanismo e de Design (Produto, Gráfico, Moda, Digital), o Programa de Pós-Graduação stricto sensu em Gestão Urbana e os cursos de pós-graduação lato sensu.

Para dar suporte à ideia de integração trazida pela organização da Universidade em Escolas, e em atendimento às exigências dos órgãos oficiais de regulamentação da educação (MEC), os documentos oficiais norteadores da EArqD, como o PPI (Projeto Pedagógico Institucional), o PPE (projeto Pedagógico da Escola) e os PPCs dos cursos (Projetos Pedagógicos de Curso) preveem ações de integração e de promoção da construção do ser global nos seus mais variados níveis, que incluem também movimentos que promovem trânsitos disciplinares. Por meio deles, entendese a interdisciplinaridade como ponto fundamental para o desenvolvimento de um indivíduo em consonância com a contemporaneidade. Segundo o PPI $(2012$, p.14) da PUCPR,

o conceito de Escola na universidade refere-se a um trabalho centrado numa construção humana coletiva, que persegue um projeto comum, por meio do qual as ações e objetivos dos agentes adquirem sentido. Pressupõe, portanto, o empenho em construir comunidade acadêmica, cuja preocupação central é o aperfeiçoamento da aprendizagem intelectual docente e discente. Assim, o sentido de pertencimento se explicita no conceito de comunidade como "um estado de espírito dinâmico e envolvente que traduz certa maneira de ser e conviver.

\title{
Segundo o Plano Pedagógico da EArqD (2013, p.12), o PPE:
}

\begin{abstract}
A Escola de Arquitetura e Design tem por objetivo central o aperfeiçoamento da aprendizagem intelectual de seus docentes e discentes, o que é almejado por meio da organização de conteúdos integrados e atividades interdisciplinares. Dessa forma, busca-se uma integração horizontal, com o relacionamento e aproveitamento dos cursos de mesmo nível entre si, e uma integração vertical, compreendida como a relação obtida pela integração de seus diversos cursos em nível de Graduação, Educação Continuada/ PósGraduação Lato Sensu, e Pós-Graduação Stricto Sensu.
\end{abstract}

Tendo por base estes conceitos, ações interdisciplinares e sinergias são adotadas para que seja valorizado um processo de ensino e aprendizagem que permita aos discentes a construção do sujeito inserido no mundo complexo, sem esquecer-se do desenvolvimento de competências necessárias aos profissionais da área. As competências almejadas são voltadas à criatividade (fantasia e concretude), à inovação, ao empreendedorismo, às técnicas e à tecnologia, à ação social, ao experimentalismo, ao planejamento e à gestão, mas também à multiculturalidade, à transdisciplinaridade, ao pensamento sistêmico e ao humanismo.

\footnotetext{
O Projeto Pedagógico da Escola de Arquitetura e Design visa a integração de ações que buscam o debate crítico, a construção coletiva e a consolidação da sua identidade, a partir da sinergia dos cursos de graduação que a compõem, na pesquisa e na extensão, pautadas pelas atuais políticas de fomento existente, com foco no aprendizado intelectual discente e docente, onde a prática do compartilhamento de princípios semelhantes e da co-criação possam interagir a favor da superação de conflitos. (NIGRO, 2013)
} 
Os projetos que a norteiam a Escola, consideram, pois a integração de ações como ponto central. Para efetivação desta proposta, além de uma integração curricular com oferta de disciplinas comuns buscando pesquisas e projetos interdisciplinares a Escola promove o desenvolvimento de Projetos Integradores e de Eventos que busquem a inter-relação entre os conhecimentos propostos no intuito de formar um individuo holístico em sua área de saber. Alguns dos projetos desenvolvidos neste âmbito são o Projeto Integrado de Arquitetura e Design e o Projeto Integrado de Temas Contemporâneos. Com relação aos eventos, a escola promove a Semana Acadêmica Integrada da Escola de Arquitetura e Design - Sincronicidade e a Semana Acadêmica de Design - Charneira. Estas ações buscam em seu cerne promover os preceitos estabelecidos nos projetos pedagógicos, em específico o de construir um ser humano apto a atuar em uma sociedade complexa dentro do conceito da transdisciplinariedade. Porém, entre a ideia da proposta e a real eficácia da mesma ainda residem questionamentos: as ações realizadas estão realmente promovendo a construção do ser humano global? As ações são percebidas como de trânsito disciplinar?

Para iniciar uma discussão sobre estes aspectos selecionou-se para um Estudo de Caso a análise dos eventos da Escola, em específico das Semanas Acadêmicas ofertadas, no intuito de verificar se elas conseguem - ou não - promover estes conceitos. Além disto, busca-se verificar se estes conceitos são apreendidos e vivenciados conscientemente pelos alunos e professores nestes eventos.

As Semanas acadêmicas são eventos estudantis comumentemente realizados no ensino superior, que tem por objetivo promover atividades de caráter científico, técnico ou cultural, com a participação conjunta dos corpos docente, discente e técnico, integrando ensino, pesquisa e extensão com a comunidade. Os itens que merecem destaques na realização das Semanas Acadêmicas são a diversidade de temas abordados pertinentes aos cursos que a promovem e a participação de professores e profissionais atuantes e reconhecidos nacional e internacionalmente, que desenvolvem palestras, participam de debates e ministram oficinas. A valorização dos profissionais egressos da universidade também é comum nas Semanas Acadêmicas, trazendo suas experiências profissionais, expectativas e desafios enfrentados, funcionando como um sinalizador de possibilidades aos alunos que ainda estão na universidade e contribuindo para a consolidação e fortalecimento de uma cultura do design e da arquitetura baseada nas transdisciplinaridade.

Em consonância com o conceito da transdisciplinaridade, a EArqD tem tido como mote principal a integração traduzida na palavra da Sincronicidade. A palavra sincronicidade para a EArqD foi tomada como sendo relativa a acontecimentos que se relacionam de forma não casual, ou seja por uma relação de significados. Pode ocorrer por meio de dois ou mais eventos que coincidam de maneira significativa para uma pessoa ou grupo de pessoas, aos quais este significado sugere um padrão uma sincronia.

A desejada sincronicidade é a busca de uma harmonia gestionável, da macro escala à micro escala, do ambiente externo ao ambiente interno, de uma escola, de um curso, de uma disciplina, de uma turma, de um professor, de um aluno, de um colaborador, no seu isolamento e no todo que rege este sistema aberto e dinâmico que é a Escola de Arquitetura e Design, orientado por seus princípios próprios, alinhados aos princípios institucionais, fundamentado por valores. (NIGRO, p.18) 
Tomando por base este conceito, a Semana Acadêmica Integrada da EArqD, denominada Sincronicidade, acontece uma vez ao ano, e é organizada e desenvolvida de forma integrada pelos acadêmicos (docentes e discentes) dos cursos de Arquitetura e Design sob a orientação dos seus professores e coordenações. A integração entre professores e alunos, na elaboração da programação, ocorre por meio dos Centros Acadêmicos de Arquitetura e Urbanismo (CAU) e de Design (CAD).

Além da Sincronicidade, realiza-se também especificamente aos cursos de design, a Charneira - Semana Acadêmica de Design, com o objetivo de promover a troca de informações entre a comunidade acadêmica e profissional do Design. A Charneira atinge também estudantes de Design de outras IES (Instituições de Ensino Superior) e tem como objetivo promover a discussão, a troca de informações e a criação de novas ideias sobre as diversas expressões do Design. O evento conta com aproximadamente 800 participantes por edição, entre estudantes, professores e profissionais renomados da área de todo o Brasil.

\subsection{Pesquisa}

Neste contexto, busca-se compreender nesta pesquisa, se as ações realizadas na tentativa de reverter a fragmentação e desconexão dos saberes têm alcançado sucesso. Para tal explora-se a problemática de como as formas de intercâmbio disciplinar (multidisciplinaridade, pluridisciplinaridade, interdisciplinaridade, transdisciplinariedade e metadisciplinaridade) estão sendo percebidas e apreendidas pelos alunos, especificamente através das Semanas Acadêmicas da Escola de Arquitetura e Design da PUCPR (Pontifícia Universidade Católica do Paraná).

Por meio de uma pesquisa quantitativa, participantes voluntários, alunos de todos os períodos dos cursos de Design Digital, Design Gráfico, Design de Produto, Design de Moda e Arquitetura e Urbanismo, responderam a um questionário objetivo no formato online, disponibilizado em dezembro de 2013 , com o intuito de levantar sua percepção quanto à efetivação do intercâmbio disciplinar promovido pelas Semanas Acadêmicas de seus cursos, em específico a do Curso de Design (Charneira) e da Escola de Arquitetura e Design (Sincronicidade), realizadas respectivamente em outubro e setembro de 2013.

O questionário versou acerca dos níveis e tipos de intercâmbios percebidos pelos alunos, acerca da expansão dos conhecimentos e ampliação dos saberes ligados à complexidade do mundo atual, acerca dos tipos de atividades - em quais se percebeu melhor a transdisciplinaridade - e, por fim, disponibilizaram palavras-chave relacionadas aos níveis de intercâmbio para que o aluno indicasse a que melhor descrevia a experiência obtida.

O questionário dividiu-se e duas partes: uma relacionada à Charneira, aplicada somente aos alunos de Design, e a segunda, com as mesmas questões, relacionada à Sincronicidade, aplicada aos alunos de Design e Arquitetura.

Questão 1 foi com relação ao período que os respondentes estavam cursando. Do total de 43 alunos respondentes, a maioria encontrava-se no 20 período do curso (15 respondentes), seguido do 6으o período (11 respondentes) e do 4 o período (9 respondentes), provindos dos cursos: Design Digital (11 respondentes), Design Gráfico (10 respondentes), Design de Produto (9 respondentes), Arquitetura e Urbanismo (7 respondentes), e Design de Moda (6 respondentes). 


\subsection{Respostas relativas à semana acadêmica de Design - Charneira}

Questão 2 - Com relação à Charneira, questionou-se que tipo de intercâmbio disciplinar teria sido o mais evidente, solicitando que os alunos enumerassem em ordem crescente (de 1 ao 5) as seguintes: Multidisciplinaridade onde não existe nenhum tipo de relação entre os conteúdos apresentados com os do curso; Pluridisciplinaridade - onde existiram relações complementares entre disciplinas mais ou menos afins; Interdisciplinaridade - onde acontece o reencontro e a cooperação entre duas ou mais disciplinas; Transdisciplinaridade - onde ocorre o máximo grau de relações entre disciplinas, promovendo uma integração global dentro de um sistema totalizador, buscando explicar a realidade sem fragmentações; Metadisciplinaridade - onde desligou-se das disciplinas, eliminando o conceito de relações entre elas e se focando no ponto de vista ou perspectiva da realidade

Constatou-se que das respostas totais (43 respondentes) somente 4 delas foram numeradas corretamente pelos participantes e consequentemente consideradas válidas. Nas outras respostas houve repetição de números de níveis, invalidando as respostas dadas. No cômpito geral verificou-se que a Pluridisciplinaridade foi a opção mais apontada como resultante das semanas acadêmicas. Os alunos justificaram as respostas. Seguem algumas relevantes:

[...] a maioria dos eventos tinham algum conteúdo interessante para o meu curso, o que trouxe a grande oportunidade de conhecer mais do que eu esperava e também, obter um conhecimento a mais.

[...] proporcionar um mundo de conhecimento e experiência que são de vidas de profissionais e alunos para alunos iniciantes e os já veteranos, é bem pouco por que é pouco tempo pra passar muita coisa, mas o suficiente que me ajudou um pouco a abrir a cabeça e ver o que é esse mundo de arquitetura e design, que ele existe e é bem mais presente do que se imagina.

Questão 3 - Tratou de levantar a percepção acerca da efetividade da semana acadêmica Charneira, em uma análise de graus que iam de 1 (sim) a 5 (não), com relação: 1. à interação com outras áreas do conhecimento; 2 . contribuição com o desenvolvimento holístico e global; e 3. oportunidades de articulação tanto dos saberes acadêmicos (como os conceituais, metodológicos, conteudísticos) quanto de saberes não acadêmicos (como a corresponsabilidade, autonomia, cidadania). Na análise das respostas verificou-se que as três concepções básicas do intercâmbio entre as disciplinas foi efetivada, sendo que a maioria respondeu sim, no primeiro grau para as três questões. As justificativas mais relevantes dadas a esta questão estão descritas a seguir:

A interação com outras áreas do conhecimento se mostram claras quando observado o panorama geral do programa, muitas escolhas extremamente distintas e que chegaram a causar dúvida na hora da escolha de palestras que concorriam no mesmo horário. Quanto ao desenvolvimento holístico, penso em partes que coube ao aluno fazer ligações desse tipo, das palestras com assuntos correlacionados.

A charneira contribuiu muito para meu conhecimento e desenvolvimento pessoal por causa da grande interação com os outros cursos que trouxe muitas experiências novas. 
Questão 4 - Buscou-se levantar quais atividades da Charneira mais proporcionaram a transdisciplinaridade da Escola, minimizando a fragmentação dos saberes. Verificou-se que na percepção de 17 alunos de design, as palestras tiveram este maior papel.

Questão 5 - Questionou-se que palavra o aluno achava que definia melhor a CHARNEIRA, tendo em vista os pares sinônimos: soma / multidisciplinaridade; contiguidade / pluridisciplinaridade; interação/interdisciplinaridade; unificação / transdisciplinaridade; libertação / metadisciplinaridade. Verificou-se que $64 \%$ dos respondentes (23 alunos) perceberam como Interação, relacionada à interdisciplinaridade, a palavra que melhor define a Charneira.

\subsection{Respostas relativas à semana acadêmica da Escola de Arquitetura e Design - Sincronicidade}

O questionário sobre a Sincronicidade foi aplicado a alunos de todos os cursos da Escola, tendo as mesmas questões do questionário especifico para os alunos de Design. Seguem-se os resultados.

Questão 2 - Relativamente a qual tipo de intercâmbio disciplinar que teria sido o mais evidente, verificou-se também que das respostas totais, somente 4 das respostas foram numeradas corretamente pelos respondentes. Da análise das respostas válidas, os alunos tiveram a percepção de que a Metadisciplinaridade foi a que mais foi significativa na Sincronicidade. Em segundo lugar encontra-se a Interdisciplinaridade, em terceiro, a Transdisciplinaridade e em último lugar a Multidisciplinaridade. Os alunos justificaram as respostas. Segue uma fala:

A Sincronicidade promoveu oportunidades em relação ao conhecimento, pelos conteúdos abordados e em relação a uma melhora pessoal e agregadora, pelos valores éticos e morais incentivados por organizadores e palestrantes.

Questão 3 - Relativa à percepção acerca da efetividade da semana acadêmica Sincronicidade, pôde-se ver que a opinião dos participantes ficou mais dividida entre os níveis de resposta. Quanto a interação com outras áreas do conhecimento, o mesmo número de respondentes (12 participantes), que equivale a $28 \%$, optou pelos níveis 1 e 3 enquanto que 21\% (9 participantes) selecionaram o nível 5; com relação ao desenvolvimento holístico e global, para 13 respondentes (30\%) a seleção foi nível 3 seguidos de $23 \%$ no nível 2 (10 alunos), 21\% no nível 1 (9 participantes) e 19\% (8 alunos) no nível 5; e no que diz respeito às oportunidades de articulação dos saberes acadêmicos e não acadêmicos prevaleceram os níveis 1 e 2, com $23 \%$ dos respondentes (10 alunos) selecionando cada um dos níveis 1 e 2 e $21 \%$ (9 alunos) optando pelo nível 5 . Nesta resposta identifica-se um maior equilíbrio de percepção das atividades, podendo ser atribuída à um equilíbrio maior entre as atividades propostas na Semana Acadêmica, que procurou atender a todos os aspectos previstos nos Projetos pedagógicos.

Questão 4 - Relativa a quais atividades da Sincronicidade mais proporcionaram a transdisciplinaridade da Escola, verificou-se que na percepção dos alunos, as palestras tiveram este maior papel. Os alunos justificaram suas respostas. Seguem 2 delas: 
Observei com mais clareza a mistura dos cursos, nas palestras, que se mostraram mais direcionadas, um dos cursos sempre se mostrava mais presente do que o outro.

Isso se justifica pelo acúmulo de conhecimento e a agregação de novas ideias.

Questão 5 - Com relação à palavra que o aluno achava que definia melhor a Sincronicidade, a maioria dos alunos (16 deles) perceberam a Interação, relacionada à interdisciplinaridade, a palavra que melhor a definiu.

\section{CONCLUSÃO}

Neste trabalho, apresentamos o resultado de uma pesquisa feita com participantes das Semanas Acadêmicas dos cursos de Design (Charneira) e de Arquitetura e Design (Sincronicidade) da Escola de Arquitetura e Design da PUCPR. O objetivo da pesquisa foi diagnosticar "se" e "que" forma de intercâmbio disciplinar (multidisciplinaridade, pluridisciplinaridade, interdisciplinaridade, transdisciplinariedade e metadisciplinaridade) foi promovida pela Escola nestes eventos e se os participantes perceberam este intercâmbio.

Pelas respostas dadas ao questionário, pode-se observar que apesar de ter havido uma leve tendência a categorizar a Semana Charneira como pluridisciplinar e a Semana Sincronicidade como metadisciplinar, os 43 respondentes, na sua maioria, acreditam que as Semanas Acadêmicas foram um evento Interdisciplinar (67\% e 37\% respectivamente) com a palavra-chave mais votada sendo definida como Interação. Este intercâmbio disciplinar ocorreu na maioria das vezes nas palestras (47\% e $65 \%$ ) do que nas mesas-redondas e workshops, contrariamente ao que poderia se esperar, pois as palestras tendem a ser eventos mais centrados no palestrista (um para todos) do que, por exemplo, nas mesas-redondas onde há uma maior discussão de pontos de vistas diferentes e complementares (alguns para todos), e nos workshops que tendem a trazer atividades mais práticas e de interação entre os participantes (todos para todos).

Somando-se a ideia de interdisciplinaridade, em ambos os eventos os participantes acreditaram que houve grande interação com as outras áreas do conhecimento ( $86 \%$ na Charneira somando-se nível 1 [ótimo] e 2 [bom], e 56\% na Sincronicidade somando-se o percentual destes dois níveis). Eles também expressaram ter havido muitas oportunidades de articulação dos saberes acadêmicos e não acadêmicos (72\% nos níveis 1 e 2 para Charneira e $46 \%$ entre os mesmos níveis para a Sincronicidade). Entretanto, com relação à contribuição com o desenvolvimento holístico e global, os respondentes se aperceberam muito mais deste aspecto na Semana Charneira onde a maioria (39\%) selecionou o nível 1 (ótimo) do que os participantes da Semana Sincronicidade, onde a maioria (30\%) optou pelo nível 3 (neutro).

Os resultados desta pesquisa preliminar corroboram com a proposta sustentada pelo PPI da Escola de Arquitetura e Design da PUCPR, que entende a interdisciplinaridade como ponto fundamental para o desenvolvimento de um indivíduo. Entretanto, busca-se galgar um nível mais alto de cooperação entre as disciplinas, onde haja inicialmente uma integração global como a proposta pela transdisciplinaridade para então atingir ao nível mais alto que é o da 
metadisciplinaridade, onde se eliminam os conceitos e compreendem a realidade como uma relação complexa, global e holística.

Já nesta pesquisa, alguns dos dados apontam levemente para a

transdisciplinaridade nas Semanas Acadêmicas Charneira e Sincronicidade, onde a palavra unificação foi a terceira mais votada ( $11 \%$ e $21 \%$ respectivamente). Isto pode indicar que alguns participantes puderam possivelmente apreender este nível de intercâmbio disciplinar, o que nos deixa otimistas para continuar desenvolvendo um trabalho que busque explicar a realidade com menos fragmentações e onde haja uma "unificação semântica e operativa das acepções através e além das disciplinas" (SOMMERMAN \& SANTOS, 2009, pag. 62, art 4․). Acredita-se, entretanto, que as Semanas Acadêmicas tenham o potencial de promover este rompimento com os paradigmas mais tradicionais de ensino e sugere-se que pesquisas como esta continuem a ser feitas para podermos diagnosticar como este intercâmbio disciplinar esta se desenvolvendo para promover os mais altos níveis de cooperação e interação da realidade nestes eventos.

\section{REFERÊNCIAS}

JULIATTO, C. I. Parceiros educadores: estudantes, professores, colaboradores e dirigentes. Curitiba: Champagnat, 2007, p.

MORIN, Edgar. Os princípios do conhecimento pertinente. In: Os sete saberes necessários à educação do futuro. São Paulo: Cortez, 2000.

NIGRO, Carlos Domingos. Fórum de Desenvolvimento da Escola de Arquitetura e Design da PUCPR. Curitiba: Monografia de especialização em Gestão e Liderança Universitária, PUCPR, 2013.

PUCPR. Projeto Pedagógico Institucional. Curitiba: PUCPR, 2013.

PUCPR. Projeto Pedagógico da Escola de Arquitetura e Design. Curitiba: PUCPR, 2013. PUCPR. Projeto Pedagógico do Curso de Arquitetura e Urbanismo. Curitiba: PUCPR, 2013.

SOMMERMAN, Américo e SANTOS, AKIKO. Complexidade e Transdisciplinaridade: em busca da totalidade perdida. Porto Alegre: Sulina, 2009.

TARDIF, M.; LESSARD, C. 0 trabalho docente: elementos para uma teoria da docência como profissão de interações humanas. Tradução de João Batista Kreuch. Petrópolis: Vozes, 2007.

ZABALA, Anton. Enfoque globalizador e pensamento complexo. Porto Alegre: Artmed, 2002. 